\title{
FAKTOR-FAKTOR OBJEKTIF DAN SUBJEKTIF YANG MEMPREDIKSI MINDFUL PARENTING PADA IBU DI INDONESIA
}

\author{
Dewi Kumalasari $^{\left.{ }^{*}\right)}$, Endang Fourianalistyawati ${ }^{2}$ \\ ${ }^{1}$ Fakultas Psikologi, Universitas YARSI, Jakarta 10510, Indonesia \\ ${ }^{2}$ School of Human Ecology, University of Wisconsin, Madison 53706, Amerika Serikat \\ *)E-mail: dewi.kumalasari@yarsi.ac.id
}

\begin{abstract}
Abstrak
Studi terdahulu menemukan sejumlah faktor yang memengaruhi mindful parenting secara terpisah. Penelitian ini bertujuan untuk menganalisis pengaruh faktor objektif dan subjektif terhadap mindful parenting pada ibu di Indonesia. Kognisi pengasuhan dalam penelitian ini terdiri atas kognisi pengasuhan positif yang diwakili oleh rasa kompeten pengasuhan dan kognisi pengasuhan negatif yang diwakili oleh atribusi berpusat pada orang tua. Penelitian ini menggunakan pendekatan kuantitatif dengan desain cross-sectional. Penelitian ini melibatkan 171 ibu yang memiliki anak usia 3-12 tahun dan dipilih melalui teknik insidental sampling. Berdasarkan analisis regresi berganda, didapatkan hasil bahwa kognisi pengasuhan yang positif dalam bentuk rasa kompeten pengasuhan dan kognisi pengasuhan negatif dalam bentuk atribusi berpusat pada orang tua dapat memprediksi mindful parenting pada ibu di Indonesia. Sementara itu, faktor-faktor objektif yang meliputi usia ibu, tingkat pendidikan, dan pengetahuan tentang pengasuhan efektif ditemukan tidak berpengaruh signifikan terhadap mindful parenting. Hal ini mengindikasikan bahwa pembentukan kognisi pengasuhan yang positif dan menghindari kognisi pengasuhan yang negatif dapat meningkatkan keterampilan mindful parenting. Untuk itu, orang-orang di sekeliling ibu juga diharapkan dapat memberikan dukungan bagi para ibu agar merasa kompeten di dalam mengasuh anak.
\end{abstract}

Kata kunci: kognisi pengasuhan, mindful parenting, pengetahuan pengasuhan efektif, tingkat pendidikan, usia ibu

\section{Identification of Objective and Subjective Factors in Predicting Mindful Parenting of Mothers in Indonesia}

\begin{abstract}
Past studies revealed several factors that influence mindful parenting separately. This study aimed to analyze the effect of objective and subjective factors on mindful parenting in mothers in Indonesia. In this study, parenting cognitions consist of positive parenting cognition represented by parenting sense of competence and negative parenting cognition represented by parent-centred attribution. This study used a quantitative approach with a cross-sectional design. This study involved 171 mothers who have children aged 3-12 years who were selected through the incidental sampling method. Based on multiple regression analysis, parent sense of competence and negative parental attribution predicted mindful parenting in Indonesian mothers. Meanwhile, objective factors including age, level of education, and knowledge of effective parenting were found not to have significant influence on mindful parenting. These findings indicate that the building of positive parenting cognitions and avoiding negative parenting cognitions can improve mindful parenting skills. For this reason, people around mothers are also expected to provide support for mothers to feel competent in parenting.
\end{abstract}

Keywords: effective parenting knowledge, level of education, mindful parenting, mothers age, parenting cognition

\section{PENDAHULUAN}

Pandemi Covid-19 telah memengaruhi banyak aspek kehidupan manusia, salah satunya pengasuhan. Adanya kebijakan Pembatasan Sosial Berskala Besar (PSBB) yang ditetapkan pemerintah sebagai tindakan preventif untuk mencegah penyebaran virus corona memaksa setiap orang untuk tetap di rumah saja, baik orang tua maupun anak. Hal ini ternyata berisiko meningkatkan kasus kekerasan pada anak. Data dari sistem informasi online perlindungan perempuan dan anak (SIMFONI PPA) mencatat sebanyak 3087 kasus kekerasan pada anak terjadi selama pandemi Covid-19 pada periode Januari-Juni 2020 (Kemen PPPA, 2020). Dalam siaran pers Menteri Pemberdayaan Perempuan dan Perlindungan Anak Nomor B016/Set/Rokum/MP 01/01/2020 disampaikan 
bahwa tingginya angka kekerasan pada anak merupakan dampak dari pengasuhan yang kurang baik (Kemen PPPA, 2020). Pernyataan tersebut terkonfirmasi oleh hasil survei pengasuhan nasional yang dilakukan KPAI yang menemukan bahwa perhatian orang tua di Indonesia untuk mencegah kekerasan pada anak masih rendah (Pranawati, Naswardi, \& Zulkarnaen, 2015). Hal ini sejalan dengan temuan Knerr, Gardner, dan Cluver (2013), rendahnya keterampilan pengasuhan menjadi faktor risiko kunci dalam maltreatment anak dan child abuse. Temuan tersebut diperkuat oleh hasil penelitian Cluver et al. (2016) yang menemukan bahwa keterampilan pengasuhan menurunkan risiko terjadinya kekerasan pada anak.

Salah satu keterampilan pengasuhan yang mendasar adalah mindful parenting (Steinberg, 2004). Mindful parenting merupakan sumber daya psikologis yang potensial dalam mengatasi stres. Stres pengasuhan terjadi ketika orang tua merasakan lebih banyak emosi negatif daripada emosi positif saat melakukan kegiatan pengasuhan (Berry \& Jones, 1995). Stres pengasuhan yang tidak teratasi dengan baik berpotensi menimbulkan praktik pengasuhan yang negatif seperti berteriak, berkata kasar ataupun memukul anak (Chung, Lanier, \& Wong, 2020). Mindful parenting dapat membantu orang tua lebih adaptif dalam menghadapi situasi yang menekan sehingga terhindar dari pengaruh negatif dari stres pengasuhan yang mereka alami.

Orang tua yang menerapkan mindful parenting akan menghadapi situasi pengasuhan dengan penuh kesadaran, lebih mampu meregulasi diri dan menghindari respon-respon yang reaktif (Duncan, Coatsworth, \& Greenberg, 2009). Dengan kata lain, mindful parenting memungkinkan orang tua untuk dapat hadir sepenuhnya saat melakukan aktivitas bersama anak, yang nantinya dapat memengaruhi kesejahteraan subjektif anak (Irzalinda, Puspitawati \& Muflikhati, 2014) serta menurunkan masalah perilaku pada anak (Bluth \& Wahler, 2011).

Kesadaran penuh terhadap interaksi pengasuhan dapat membuat orang tua memberikan jeda dan mengalihkan perhatian mereka untuk meninjau pengalaman pengasuhan yang sedang mereka lakukan dalam konteks relasi jangka panjang yang mereka miliki dengan anak. Beberapa hasil studi menemukan bahwa mindful parenting terbukti menurunkan stres pengasuhan pada orang tua yang mengasuh anak berkebutuhan khusus, seperti anak ADHD (Oord, Bögels, \& Peijnenburg, 2012) dan anak dengan keterlambatan perkembangan (Neece, 2014).

Selain dalam konteks anak berkebutuhan khusus, mindful parenting juga terbukti berperan dalam rendahnya stres pengasuhan pada ibu yang mengasuh anak dengan perkembangan normal (Gani \& Kumalasari, 2019; Kumalasari \& Fourianalistyawati, 2020). Hal ini diperkirakan karena mindful parenting berperan dalam membangkitkan kesiapan serta kesediaan untuk terus belajar menghadapi kesulitan-kesulitan yang muncul dalam melakukan tugas pengasuhan (Lestari, 2012). Duncan et al. (2009) menemukan bahwa mindful parenting dapat meningkatkan perilaku pengasuhan yang efektif serta menurunkan perilaku pengasuhan yang tidak efektif. Orang tua yang mengimplementasikan keterampilan mindful parenting dalam interaksinya dengan anak, mereka akan mengembangkan kapasitas pengasuhannya secara konsisten dan sejalan dengan tujuan serta nilai-nilai yang dimiliki, disertai dengan kehangatan dan relasi yang mengayomi dalam hubungan antara orang tua dan anak.

Beberapa penelitian sebelumnya menemukan faktor-fakor yang memengaruhi mindful parenting. Penelitian yang dilakukan oleh Lo et al. (2018) dengan sampel orang tua di Hongkong menemukan bahwa usia orang tua berperan terhadap mindful parenting. Tingkat pendidikan juga ditemukan berasosiasi dengan mindful parenting. Orang tua yang memiliki tingkat pendidikan yang lebih tinggi diasosiasikan dengan memiliki kesempatan yang lebih baik untuk memperoleh pengetahuan mendalam dan keterampilan terkait dengan pengasuhan dan hubungan orang tua-anak (Gouveia et al., 2016).

Selain faktor demografis tersebut, pengetahuan orang tua tentang pengasuhan juga diperkirakan dapat memprediksi mindful parenting. Pengetahuan orang tua diketahui memiliki kaitan erat dengan kualitas pengasuhan. Orang tua yang mampu menampilkan pengetahuan tentang strategi pengasuhan positif dilaporkan memiliki tingkat disfungsi pengasuhan yang lebih rendah (Winter, Morawska, \& Sanders, 2012). Hal ini diperkirakan karena pengetahuan orang tua tentang pengasuhan dan perkembangan anak akan membuat orang tua memahami norma perkembangan anak dan strategi dalam mengasuh anak yang akan membantu orang tua dalam memenuhi kebutuhan biologis, fisik, sosial emosional, dan kognitif anak (Bornstein, 
Putnick, \& Suwalsky, 2018). Pengetahuan tentang proses dan tahapan perkembangan anak, memungkinkan orang tua memiliki mekanisme kognitif global untuk mengantisipasi dan merespon perubahan-perubahan perkembangan anak. Dengan kata lain, pengetahuan tentang pengasuhan merupakan sumber daya yang dapat membantu orang tua agar mampu menerapkan mindful parenting pada anak. Usia, latar belakang pendidikan, dan pengetahuan orang tua tentang pengasuhan efektif dapat dikategorikan sebagai faktor objektif yang dapat memprediksi mindful parenting.

Di samping faktor yang bersifat objektif, penelitian terdahulu juga menemukan faktor subjektif yang dapat memengaruhi mindful parenting. Penelitian Lippold et al. (2019) dan juga penelitian Sanders dan Morawska (2018) menemukan bahwa persepsi orang tua tentang penilaian diri dalam menjalankan perannya sebagai pendidik dan pengasuh berkorelasi positif dengan mindful parenting. Persepsi orang tua tentang penilaian diri di dalam menjalankan perannya dikenal sebagai kognisi pengasuhan. Kognisi pengasuhan dapat memengaruhi motivasi orang tua untuk terlibat dalam pengasuhan ketika menghadapi tantangan. Kognisi pengasuhan memiliki dua bentuk yaitu kognisi pengasuhan positif dan kognisi pengasuhan negatif (Lippold et al., 2019).

Kognisi pengasuhan positif diwakili oleh rasa kompeten pengasuhan, sementara itu kognisi pengasuhan negatif diwakili oleh atribusi yang berpusat pada orang tua terhadap perilaku anak. Orang tua yang merasa kompeten dalam menjalankan peran dan tugasnya, mereka akan lebih persisten ketika menghadapi situasi pengasuhan yang menantang, tidak menarik diri dari situasi tersebut, serta memiliki stres pengasuhan yang lebih rendah (Benedetto \& Ingrassia, 2018). Sebaliknya, rasa kompeten yang rendah dan atribusi negatif seperti menyalahkan diri sendiri (self-blame) dapat menurunkan motivasi untuk persisten dalam menghadapi tantangan pengasuhan dan meningkatkan respon afektif yang negatif terhadap perilaku anak (Bugental et al., 1998).

Berdasarkan paparan di atas, tampak bahwa studi terdahulu banyak meneliti faktor-faktor yang memengaruhi mindful parenting secara terpisah. Lebih jauh, dalam konteks masyarakat Indonesia, penelitian mengenai faktor-faktor yang memprediksi mindful parenting masih belum ditemukan. Padahal, budaya dapat turut memengaruhi proses pengasuhan yang terjadi
(Bornstein, Putnick, \& Lansford, 2011). Untuk melengkapi studi sebelumnya yang dilakukan oleh Gouveia et al. (2016), Lo et al. (2018), dan Winter et al. (2012) tentang faktor objektif yang memengaruhi mindful parenting; Lippold et al. (2019) dan Sanders dan Morawska (2018) tentang faktor subjektif yang memengaruhi mindful parenting, penelitian ini berusaha mengungkap pengaruh kedua faktor tersebut secara bersama-sama terhadap mindful parenting untuk mendapatkan gambaran yang komprehensif mengenai faktor-faktor yang dapat memprediksi mindful parenting.

Penelitian ini berfokus pada populasi ibu dengan pertimbangan ibu diketahui memiliki pengaruh yang lebih besar terhadap perkembangan anak dibandingkan ayah (Meunier, Roskam, \& Browne, 2011). Di sisi lain, ibu memiliki stres pengasuhan yang lebih tinggi dibandingkan ayah (Widarsson et al., 2013) serta diketahui memiliki indeks pengasuhan yang rendah (Aritonang, Hastuti, \& Puspitawati, 2020). Gambaran yang komprehensif mengenai faktor-faktor yang memprediksi mindful parenting dapat menjadi landasan intervensi untuk mengembangkan keterampilan mindful parenting pada ibu di Indonesia berdasarkan temuan penelitian ini. Dengan demikian, penelitian ini bertujuan untuk (1) mengidentifikasi faktor-faktor objektif (usia, tingkat pendidikan, pengetahuan pengasuhan efektif), subjektif (kognisi pengasuhan) dan mindful parenting; (2) menganalisis pengaruh faktor objektif dan subjektif secara bersamasama terhadap mindful parenting pada ibu di Indonesia. Berangkat dari tujuan penelitian tersebut, peneliti membangun hipotesis bahwa faktor objektif dan faktor subjektif dapat memprediksi mindful parenting pada ibu di Indonesia.

\section{METODE}

Penelitian ini menggunakan pendekatan kuantitatif dengan desain cross-sectional study. Pendekatan kuantitatif dipilih karena penelitian ini bertujuan untuk menguji hipotesis melalui teknik uji statistik dari data penelitian yang berbentuk angka. Lebih lanjut, dikarenakan kondisi pandemi yang membuat interaksi tatap muka menjadi terbatas, penyebaran kuesioner dilakukan secara daring dengan menggunakan Google Forms. Peneliti menyebarkan tautan kuesioner ke media sosial dan jejaring yang dimiliki di seluruh Indonesia, sejalan dengan tujuan penelitian untuk mengidentifikasi faktor yang memengaruhi mindful parenting pada ibu di Indonesia. Waktu pengambilan data 
dilakukan selama 1 bulan, dari 11 Juni hingga 6 Juli 2020.

Populasi penelitian adalah ibu yang memiliki anak berusia 3-12 tahun. Spesifikasi sampel pada ibu yang mengasuh anak usia 3 hingga 12 tahun didasarkan argumentasi bahwa pada usia tersebut merupakan periode saat tanggung jawab orang tua berada pada titik terluas dan intens terkait dengan seluruh aspek wellbeing (kesejahteraan) anak, mencakup kehidupan, kesehatan, keamanan fisik dan emosional, pengasuhan, kesempatan belajar dan kebebasan berekspresi (Oates, 2010). Teknik sampling yang digunakan adalah incidental sampling, yaitu subjek yang memenuhi kriteria dapat turut serta mengisi kuesioner.

Jenis data yang dikumpulkan dalam penelitian ini merupakan data primer. Data primer dikumpulkan melalui kuesioner yang diisi secara self-report, meliputi karakteristik partisipan yang mencakup usia dan latar belakang pendidikan, pengetahuan tentang pengasuhan efektif, atribusi berpusat pada orang tua, rasa kompeten pengasuhan, dan mindful parenting.

Pengetahuan tentang pengasuhan efektif merefleksikan pengetahuan pengasuhan pada empat area, yaitu peningkatan perkembangan (perkembangan hubungan positif, mendorong perilaku yang diharapkan dan mengajarkan keterampilan dan perilaku baru), prinsip-prinsip pengasuhan efektif (memasukkan lingkungan yang aman dan menarik, menciptakan lingkungan belajar yang positif, memiliki harapan yang realistis dan merawat diri sendiri sebagai orang tua), menggunakan disiplin yang asertif dan mengidentifikasi penyebab masalah perilaku (Winter et al., 2012). Variabel ini diukur dengan menggunakan instrumen Knowledge of Effective Parenting Scale (KEPS). Jumlah pertanyaan dalam instrumen ini sebanyak 28 pertanyaan berupa sebuah kasus dan responden diminta untuk menentukan strategi pengasuhan yang efektif untuk mengatasi kasus tersebut, contohnya "Selama perjalanan berbelanja di toko kelontong, Andi meminta ibunya untuk membelikannya mainan. Ibunya berkata tidak hari ini. Andi protes, memohon pada ibu untuk membeli mainan yang dia inginkan. Ibunya tetap mengatakan tidak. Andi mulai menangis kemudian berteriak dengan keras melemparkan dirinya ke lantai. Andi lebih cenderung membuat ulah di masa depan saat berbelanja dengan ibunya jika ibunya". Pada setiap pertanyaan, disediakan empat pilihan jawaban, yang terdiri atas satu jawaban benar dan tiga jawaban salah. Skoring yang dilakukan adalah skor 1 (satu) untuk setiap jawaban benar dan 0 (nol) untuk jawaban salah. Indeks reliabilitas (Cronbach's alpha) instrumen KEPS adalah 0,73 .

Atribusi berpusat pada orang tua merefleksikan pemikiran orang tua yang menyalahkan diri mereka sendiri atas perilaku anak (Lippold et al., 2019). Atribusi berpusat pada orang tua diukur menggunakan instrumen Parentcentered Attribution (PA). PA mengukur kognisi pengasuhan negatif yaitu frekuensi orang tua berpikir bahwa mereka yang bertanggung jawab atas perilaku anak. Jumlah butir dalam instrumen ini sebanyak lima pernyataan, contohnya "Ketika anak saya berperilaku yang tidak seharusnya, saya seringkali meyakini itu adalah karena saya menangani anak saya dengan cara yang tidak percaya diri". Pada setiap pernyataan, subjek diminta untuk menentukan seberapa sering mereka meyakini pernyataan tersebut dengan lima pilihan respon yang dapat dipilih, yaitu $0=$ tidak pernah, 1 =jarang, 2=kadang-kadang, 3=sering, dan 4=selalu. Indeks reliabilitas (Cronbach's alpha) dari instrumen PA adalah 0,83.

Rasa kompeten pengasuhan merefleksikan perasaan mampu orang tua menjalankan peran pengasuhan (Gibaud-Wallston \& Wandersman, 1978). Rasa kompeten pengasuhan diukur menggunakan instrumen Parenting competence (PC) yang dikembangkan oleh Gibaud-Wallston dan Wandersman (1978). PC mengukur keyakinan orang tua bahwa mereka mampu menjalankan peran sebagai orang tua. Keyakinan tersebut dioperasionalisasi dalam enam butir, contohnya "Sejujurnya, saya percaya bahwa saya memiliki semua keterampilan yang diperlukan untuk menjadi ibu/ayah yang baik untuk anak saya". Pada setiap butir pernyataan, tersedia enam pilihan respon yang dapat dipilih, yaitu $0=$ sangat tidak setuju, 1=tidak setuju, 2=agak tidak setuju, 3=agak setuju, 4=setuju, dan 5=sangat setuju. Indeks reliabilitas (Cronbach's alpha) dari instrumen PC adalah 0,83.

Mindful parenting merefleksikan kesadaran penuh orang tua dalam kegiatan pengasuhan yang tampak dari perilaku mendengarkan dengan penuh perhatian, penerimaan terhadap diri sendiri dan anak tanpa penghakiman, regulasi diri dalam hubungan pengasuhan, kesadaran terhadap emosi diri sendiri dan anak serta rasa belas kasih terhadap diri sendiri dan anak (Duncan et al., 2009). Mindful parenting diukur dengan menggunakan instrumen Interpersonal Mindfulness in Parenting (IMP) yang dikembangkan oleh Duncan et al. (2009) 
untuk mengukur mindful parenting. IMP mengukur praktik pengasuhan orang tua dalam mendengarkan anak dengan penuh perhatian, penerimaan tanpa penghakiman, kesadaran emosional, regulasi diri dalam pengasuhan serta belas kasih terhadap diri sendiri dan anak. Jumlah butir dalam instrumen IMP adalah 31 pernyataan mengenai pengalaman pengasuhan sehari-hari, contohnya "Saya memberikan perhatian penuh pada anak saya ketika kami menghabiskan waktu bersama". Pada setiap pernyataan, subjek diminta untuk menentukan seberapa sering mereka meyakini pernyataan tersebut dengan lima pilihan respon yang dapat dipilih, yaitu $0=$ tidak pernah, $1=$ jarang, 2=kadang-kadang, 3=sering, dan 4=selalu. Indeks reliabilitas (Cronbach's alpha) dari instrumen IMP adalah 0,88.

Teknik analisis data yang digunakan dalam penelitian ini adalah uji beda dan regresi berganda. Uji beda dilakukan dengan teknik ANOVA untuk menguji perbedaan mindful parenting berdasarkan latar belakang pendidikan. Sementara itu, uji regresi berganda dilakukan untuk melihat peran masing-masing variabel terhadap mindful parenting. Seluruh analisis data dilakukan melalui software Jeffreys's Amazing Statistics Program (JASP) versi 0.13.1.0.

\section{HASIL}

\section{Karakteristik Ibu}

Partisipan yang terlibat dalam penelitian ini berjumlah 198 ibu. Namun setelah dilakukan data cleaning, 27 data tidak dilanjutkan dalam pengolahan data karena tampak tidak menjawab dengan jawaban yang sebenarbenarnya (terlihat dari kecenderungan menjawab dengan jawaban yang sama baik pada aspek favorable maupun unfavorable). Dengan demikian, partisipan yang diperhitungkan dalam penelitian ini adalah 171 orang.

Secara umum, partisipan dalam penelitian ini berada pada rentang usia 26-53 tahun ( $M=36,1$, $\mathrm{SD}=4,95)$, memiliki tingkat pendidikan yang beragam dari sekolah menengah hingga pascasarjana, berdomisili dari wilayah yang beragam di Indonesia. Lebih lanjut, partisipan dalam penelitian ini memiliki status pekerjaan serta jumlah anak yang beragam. Tabel 1 menunjukkan bahwa mayoritas responden berlatar belakang Pendidikan Sarjana $(53,22$ persen), berdomisili di Pulau Jawa $(60,24$ persen), berstatus bekerja tetap (35,67 persen) dan memiliki dua orang anak (35,67 persen).
Tabel 1 Data demografi

\begin{tabular}{llrr}
\hline \multicolumn{1}{c}{ Variabel } & \multicolumn{1}{c}{ Kategori } & $\mathrm{n}$ & \multicolumn{1}{c}{$\%$} \\
\hline Tingkat & Sekolah & 13 & 7,60 \\
& menengah & & \\
& Diploma & 20 & 11,69 \\
& Sarjana & 91 & 53,22 \\
& Pascasarjana & 47 & 27,49 \\
\hline Domisili & Jakarta & 30 & 17,54 \\
& Pulau Jawa & 103 & 60,24 \\
& Pulau Sumatera & 25 & 14,61 \\
& Pulau Sulawesi & 10 & 5,86 \\
& Pulau Bali dan & 2 & 1,17 \\
& Nusa Tenggara & & \\
& Pulau Papua & 1 & 0,58 \\
\hline Pekerjaan & Ibu rumah & 54 & 31,58 \\
& tangga penuh & & \\
& Bekerja tetap & 61 & 35,67 \\
& Wirausaha & 19 & 11,11 \\
& Lainnya & 37 & 21,64 \\
& (freelance) & & \\
\hline Jumlah anak & 1 & 31 & 18,12 \\
& 2 & 61 & 35,67 \\
& 3 & 54 & 31,58 \\
& 4 & 18 & 10,53 \\
& $\geq 5$ & 7 & 4,10 \\
\hline
\end{tabular}

Keterangan: $n=j u m l a h ; \%=$ persen

\section{Perbedaan Mindful Parenting berdasarkan Tingkat Pendidikan}

Berdasarkan data yang terkumpul, dilakukan identifikasi faktor-faktor objektif dan subjektif yang berkaitan dengan mindful parenting. Faktor objektif terdiri atas variabel latar belakang pendidikan, usia ibu, dan pengetahuan tentang pengasuhan efektif. Faktor subjektif terdiri atas variabel rasa kompeten pengasuhan dan atribusi berpusat pada orang tua. Selain identifikasi data, dilakukan juga uji beda agar hasil penelitian yang disajikan lebih mendalam.

Uji beda dilakukan pada variabel latar belakang pendidikan yang merupakan jenis data kategorik. Hasil analisis menunjukkan bahwa responden dalam penelitian ini memiliki beragam latar belakang pendidikan, dari SMA hingga S3, yang dikategorikan dalam empat kelompok, yaitu sekolah menengah, diploma, sarjana, dan pasca sarjana. Selanjutnya, dilakukan uji beda untuk melihat signifikansi perbedaan mindful parenting berdasarkan tingkat pendidikan (Tabel 2).

Berdasarkan hasil analisis, terlihat signifikansi $>0,001$ dengan nilai $F=0,273$ yang mengindikasikan bahwa tidak ada perbedaan mindful parenting berdasarkan tingkat pendidikan. Oleh karena itu, dapat disimpulkan bahwa tingkat pendidikan tidak terkait dengan mindful parenting pada ibu di Indonesia. 
Tabel 2 Uji beda mindful parenting berdasarkan tingkat pendidikan

\begin{tabular}{lrrrrr}
\hline \multicolumn{1}{c}{ Tingkat pendidikan } & Rata-rata & Standar deviasi & Jumlah responden & $\mathrm{F}$ & $\mathrm{P}$ \\
\hline Sekolah menengah atas & 116,769 & 12,551 & 13 & 0,273 & 0,845 \\
Diploma & 113,667 & 10,556 & 20 & & \\
Sarjana & 114,581 & 12,836 & 91 & & \\
Pasca sarjana & 113,468 & 12,439 & 47 & & \\
\hline
\end{tabular}

\section{Pengaruh Rasa Kompeten Pengasuhan dan Atribusi Berpusat Pada Orang Tua terhadap Mindful Parenting}

Pengujian selanjutnya adalah uji regresi berganda mindful parenting dengan dua prediktor, yaitu rasa kompeten pengasuhan dan atribusi berpusat pada orang tua (Tabel 3). Hasil analisis memperlihatkan bahwa nilai signifikansi $<0,001$ dengan nilai $F=38,048$. Hal ini mengindikasikan bahwa hipotesis dalam studi ini diterima. Oleh karena itu, dapat disimpulkan bahwa kognisi pengasuhan dapat memprediksi mindful parenting pada ibu di Indonesia.

Selanjutnya, dari tabel tersebut terlihat bahwa baik variabel rasa kompeten pengasuhan maupun atribusi berpusat pada orang tua berperan sebesar 28,5 persen dalam memprediksi mindful parenting pada ibu di Indonesia. Sementara itu, 71,5 persen dari mindful parenting dapat diprediksi oleh faktor lain yang tidak diukur dalam penelitian ini. Peran masing-masing variabel dapat dilihat pada kolom standardized coefficient beta. Dari hasil uji regresi didapatkan konstanta sebesar 93,455 . Hal ini mengindikasikan bahwa jika rasa kompeten pengasuhan $(P C)$ dan atribusi berpusat pada orang tua (PA) memiliki skor 0 , maka skor mindful parenting yg didapatkan adalah 93,455.

Tabel 3 Hasil uji regresi

\begin{tabular}{|c|c|c|c|c|c|}
\hline \multirow[t]{2}{*}{ Model } & \multicolumn{2}{|c|}{$\begin{array}{c}\text { Coefficient } \\
\text { unstandardize } \\
d\end{array}$} & \multirow{2}{*}{$\begin{array}{c}\begin{array}{c}\text { Standardi } \\
\text { zed } \\
\text { coefficien } \\
t\end{array} \\
\text { Beta }\end{array}$} & \multirow[t]{2}{*}{$\mathrm{T}$} & \multirow[t]{2}{*}{ Sig } \\
\hline & B & $\begin{array}{l}\text { Std } \\
\text { Error }\end{array}$ & & & \\
\hline (Constant) & $\begin{array}{r}93,4 \\
55\end{array}$ & 6,607 & & $\begin{array}{r}14,1 \\
44\end{array}$ & $\begin{array}{l}<0, \\
001\end{array}$ \\
\hline $\begin{array}{l}\text { Rasa } \\
\text { kompeten } \\
\text { pengasuhan }\end{array}$ & $\begin{array}{r}0,77 \\
3\end{array}$ & 0,148 & 0,361 & $\begin{array}{r}5,24 \\
0\end{array}$ & $\begin{array}{l}<0, \\
001\end{array}$ \\
\hline $\begin{array}{l}\text { Atribusi } \\
\text { berpusat } \\
\text { pada orang } \\
\text { tua }\end{array}$ & $\begin{array}{r}0,96 \\
5\end{array}$ & 0,225 & $-0,296$ & $\begin{array}{r}4,29 \\
7\end{array}$ & $\begin{array}{l}<0, \\
001\end{array}$ \\
\hline \multicolumn{6}{|c|}{$R^{2}=0,285$} \\
\hline
\end{tabular}

Sementara itu, dari nilai koefisien beta terlihat bahwa variabel rasa kompeten pengasuhan dan atribusi berpusat pada orang tua memiliki besaran yang cukup setara namun dalam arah yang berbeda, yaitu rasa kompeten memiliki nilai positif dan atribusi berpusat pada orang tua memiliki nilai negatif. Hal ini menunjukkan bahwa nilai rasa kompeten pengasuhan yang tinggi akan meningkatkan skor mindful parenting, sedangkan skor atribusi berpusat pada orang tua yang tinggi akan menurunkan skor mindful parenting. Peningkatan satu skor pada rasa kompeten pengasuhan akan meningkatkan mindful parenting sebesar 0,361, sebaliknya peningkatan satu skor pada atribusi berpusat pada orang tua akan menurunkan mindful parenting sebesar 0,296.

\section{PEMBAHASAN}

Berdasarkan hasil penelitian ini diketahui bahwa kognisi pengasuhan merupakan faktor yang memprediksi mindful parenting pada ibu di Indonesia. Kognisi pengasuhan dapat berbentuk positif maupun negatif. Pada penelitian ini kognisi pengasuhan yang positif diwakili oleh rasa kompeten pengasuhan (parent sense of competence). Sementara itu, kognisi pengasuhan yang negatif diwakili oleh atribusi berpusat pada orang tua tentang masalah perilaku anak (parent attribution). Penelitian ini mengungkapkan, kognisi pengasuhan yang positif akan memprediksi tingginya mindful parenting, sebaliknya kognisi pengasuhan yang negatif akan memprediksi rendahnya mindful parenting. Hasil ini memperkuat penelitian sebelumnya (Lippold et al., 2019) yang menemukan bahwa mindful parenting memiliki keterkaitan dengan kognisi pengasuhan, baik kognisi pengasuhan yang positif maupun negatif.

Hasil penelitian ini menunjukkan bahwa kognisi pengasuhan positif berpengaruh terhadap tingginya mindful parenting. Orang tua dengan kognisi pengasuhan positif ditandai dengan perasaan kompeten dalam menjalankan peran sebagai orang tua. Pada berbagai domain kehidupan, individu yang merasa kompeten cenderung menampilkan performa yang lebih baik (Johnston \& Taylor, 2018). Demikian pula 
pada pengasuhan, rasa kompeten pengasuhan yang tinggi ditemukan memprediksi praktik pengasuhan yang positif (Dumka et al., 2010), juga dapat membantu orang tua untuk menikmati peran sebagai orang tua dan dapat meningkatkan keterlibatan dalam pengasuhan melalui perilaku suportif yang lebih intens dan efektif dalam penerapan disiplin dan pemantauan (Shumow \& Lomax, 2002; Slagt et al., 2012). Sebaliknya, rasa kompeten yang rendah ditemukan berpengaruh terhadap praktik pengasuhan yang negatif (Rachmawati \& Hastuti, 2017).

Orang tua yang merasa kompeten lebih cenderung bertindak dengan kesadaran penuh (mindful) dalam perilaku pengasuhan. Hal ini sejalan dengan penelitian longitudinal di Amerika Serikat yang menemukan bahwa semakin positif kognisi pengasuhan diasosiasikan dengan semakin tingginya tingkat mindful parenting (Lippold et al., 2019). Orang tua yang menilai dirinya lebih kompeten dan memiliki lebih sedikit atribusi negatif yang berpusat pada dirinya cenderung lebih mindful dalam proses pengasuhan. Tingginya mindful parenting ini juga meningkatkan keterlibatan mereka pada anak. Orang tua dengan penilaian kompetensi diri yang baik ini juga lebih mampu untuk menjalani perannya sebagai orang tua dan lebih termotivasi untuk bertahan saat menghadapi tantangan dalam menjalani peran tersebut (Bugental et al., 1998).

Lebih lanjut, ibu yang yakin bahwa dirinya mampu dan kompeten dalam menjalankan peran sebagai orang tua cenderung lebih responsif, hangat, dan empatik (Benedetto \& Ingrassia, 2018; Meunier et al., 2011). Hal ini dapat dijelaskan melalui dimensi-dimensi yang ada pada mindful parenting. Responsivitas diperkirakan muncul karena orang tua memusatkan perhatian secara penuh saat berinteraksi dengan anak. Saat berinteraksi, orang tua perlu memberikan perhatian penuh serta memahami pesan yang disampaikan anak. Pesan tersebut dapat berupa kata-kata maupun bahasa tubuh. Lebih lanjut, pesan tersebut dapat menjadi petunjuk bagi orang tua untuk memahami kebutuhan maupun maksud anak (Duncan et al., 2009). Selain itu, responsivitas juga diperkirakan terbentuk karena adanya kesadaran emosional yang baik terhadap anak. Apabila orang tua mampu mengidentifikasi emosi, baik emosi diri sendiri maupun emosi anak, dengan kesadaran penuh dalam berinteraksi, orang tua menjadi mampu untuk membuat pilihan sadar mengenai cara berespon terhadap anak, daripada bereaksi secara otomatis terhadap situasi pengasuhan
(Duncan et al., 2009). Selanjutnya, respon yang tampil dalam bentuk kehangatan dan sikap empatik diperkirakan muncul karena adanya rasa belas kasih (compassion) terhadap anak. Melalui belas kasih terhadap anak, orang tua yang mindful (berkesadaran penuh) akan merasakan keinginan untuk memenuhi kebutuhan anak yang sesuai, dan menghibur kesusahan yang mungkin dirasakan oleh anak tersebut (Duncan et al., 2009).

Ibu yang memiliki rasa kompeten yang tinggi dalam pengasuhan juga ditemukan tidak sering menghukum anak (Meunier et al., 2011). Bandura (2012) menambahkan bahwa orang tua yang merasa kompeten dan tidak menyalahkan diri sendiri dalam proses pengasuhan dapat menunjukkan peningkatan regulasi emosional dan lebih mampu mengendalikan reaksi spontan terhadap perilaku anak. Jika dikaitkan dengan dimensi pada mindful parenting, hal ini diperkirakan muncul karena dimensi penerimaan tanpa penghakiman dan regulasi diri. Dimensi penerimaan tanpa penghakiman memungkinkan orang tua memiliki pemahaman penuh mengenai anak mereka (Duncan et al., 2009). Orang tua menjadi tidak mudah menilai bahwa perilaku anak mereka adalah sesuatu yang salah dan pantas mendapat hukuman. Orang tua menjadi lebih peka terhadap kebutuhan anak sehingga mampu memahami sebab anak menampilkan perilaku tertentu yang kemudian membuat orang tua lebih mampu mengelola dirinya dalam mengasuh anak, dengan memilih respon-respon yang sesuai dengan tujuan pengasuhan.

Selanjutnya, ibu yang yakin bahwa dirinya mampu dan kompeten dalam menjalankan peran sebagai orang tua juga ditemukan cenderung lebih memiliki ekspektansi yang sesuai (Meunier et al., 2011). Hal ini terkait dengan dimensi penerimaan tanpa penghakiman dalam dimensi mindful parenting. Orang tua yang mindful dicirikan dengan penerimaan terhadap anak mereka yang kemudian membentuk ekspektansi yang sesuai dengan konteks budaya dan tingkat perkembangan anak (Duncan et al., 2009). Dengan kata lain, perasaan kompeten orang tua dalam mengasuh anak mereka akan memunculkan penerimaan terhadap anak sehingga cenderung menetapkan harapanharapan yang sesuai dengan kondisi anak. Dengan demikian, dapat disimpulkan bahwa kognisi pengasuhan yang diwakili oleh rasa kompeten pengasuhan dapat memprediksi kesadaran orang tua akan proses pengasuhan yang dijalaninya melalui proses memberikan 
perhatian secara bertujuan, berfokus pada saat ini dan tanpa penghakiman atas setiap kejadian dalam konteks relasi orang tua-anak.

Hasil penelitian ini menunjukkan, kognisi pengasuhan negatif berpengaruh terhadap rendahnya mindful parenting. Kognisi pengasuhan negatif ditandai dengan atribusi berpusat pada orang tua terkait masalah perilaku pada anak. Atribusi adalah pemaknaan tentang sebab dari peristiwa atau perilaku. Pada atribusi negatif, orang tua menjadi cenderung menyalahkan dirinya sendiri sebagai sumber masalah perilaku pada anak. Park et al. (2018) menyebutkan bahwa kognisi pengasuhan yang negatif akan secara otomatis memicu individu untuk mempersepsikan situasi yang dihadapi sebagai situasi yang penuh tekanan. Dalam situasi pengasuhan yang penuh tekanan, orang tua mungkin akan meresponnya dengan bertindak terhadap anak (fight), lari dari kondisi tersebut (flight) ataupun hanya diam saja (freeze). Respon tercepat individu dalam kondisi tertekan biasanya diambil melalui rute terpendek di otak, yang berlokasi di batang otak. Batang otak bertanggung jawab terhadap respon fight-flightfreeze, dikombinasikan dengan area limbik. Rute pendek ini tidak melewati pre-frontal cortex, yang merupakan bagian penting dalam memberikan perhatian (paying attention) (Bögels et al., 2014). Hal ini yang diperkirakan membuat orang tua dengan kognisi pengasuhan yang negatif akan menghambat orang tua dalam menerapkan mindful parenting, sejalan dengan temuan Farb, Anderson, dan Segal (2012) bahwa pre-frontal cortex adalah bagian otak yang berperan dalam mindfulness.

Secara lebih spesifik, atribusi berpusat pada orang tua terhadap dirinya sendiri sebagai sumber masalah perilaku pada anak akan menurunkan penerimaan diri orang tua tentang segala hal yang terjadi dalam kegiatan pengasuhan. Hal ini bertentangan dengan dimensi penerimaan tanpa penghakiman dalam konsep mindful parenting. Orang tua yang mindful dicirikan dengan adanya penerimaan bahwa proses pengasuhan bisa jadi sangat menantang dan menyadari bahwa setiap tantangan pengasuhan yang dihadapi dan kesalahan pengasuhan yang dibuat adalah hal yang wajar (Duncan et al., 2009). Dengan kata lain, atribusi negatif membuat orang tua memberikan penghakiman pada diri mereka sendiri yang akhirnya menyulitkan orang tua untuk menyadari bahwa hal-hal yang terjadi dalam pengasuhan adalah hal yang wajar sehingga tidak perlu menyalahkan diri sendiri.
Lebih jauh, sikap orang tua yang menyalahkan diri sendiri akan masalah perilaku pada anak juga bertentangan dengan dimensi belas kasih pada konsep mindful parenting. Orang tua yang mindful dicirikan dengan sikap menghindari menyalahkan diri sendiri ketika tujuan pengasuhan anak tidak tercapai, yang memungkinkan keterlibatan kembali dalam mengejar tujuan pengasuhan anak (Duncan et al., 2009). Dengan kata lain, atribusi berpusat pada orang tua akan menyulitkan orang tua untuk dapat mengurangi ancaman evaluatif sosial yang mungkin dirasakan oleh orang tua yang merasa dihakimi oleh orang lain sehubungan dengan perilaku pengasuhan mereka sendiri atau perilaku anak mereka di muka umum. Lebih jauh, atribusi pengasuhan yang negatif pada ibu berpengaruh positif signifikan terhadap perilaku pengasuhan yang kasar (harsh parenting) (Wang \& Wang, 2018).

Dari paparan di atas, tampak bahwa perasaan kompeten dan rendahnya atribusi negatif dapat membantu orang tua untuk lebih menyayangi diri dan anaknya, menjadi kurang reaktif dan lebih 'hadir' saat bersama anak (Duncan et al., 2009). Orang tua dengan kognisi pengasuhan yang positif akan merasa lebih kompeten dan memiliki lebih sedikit atribusi negatif terhadap dirinya cenderung lebih mindful dalam pengasuhan. Orang tua yang merasa kompeten lebih cenderung bertindak dengan kesadaran penuh (mindful) dalam perilaku pengasuhan. $\mathrm{Hal}$ ini menunjukkan bahwa kognisi pengasuhan memainkan peran penting dalam kemampuan orang tua untuk hadir, tidak menghakimi dan menyayangi anak mereka.

Salah satu temuan menarik dalam penelitian ini adalah mindful parenting tidak berkaitan dengan usia orang tua, pengetahuan tentang pengasuhan efektif, dan tingkat pendidikan. Hal ini bertentangan dengan hasil penelitian di Hongkong yang menemukan bahwa usia orang tua memengaruhi mindful parenting, semakin tua usia orang tua, semakin meningkat mindful parenting (Lo et al., 2018) serta bertentangan dengan hasil penelitian Gouveia et al. (2016) yang menemukan bahwa tingkat pendidikan memengaruhi mindful parenting. Hal ini diperkirakan karena adanya perbedaan sampel penelitian. Penelitian Lo et al. (2018) melibatkan sampel orang tua yang mengasuh anak berusia prasekolah, usia sekolah dasar dan usia sekolah menengah, berbeda dengan penelitian ini yang hanya melibatkan orang tua anak usia prasekolah dan usia sekolah dasar. Hal ini memungkinkan rentang usia responden dalam penelitian Lo et al. (2018) lebih lebar daripada rentang usia responden dalam 
penelitian ini sehingga temuan penelitiannya pun berbeda. Lebih jauh, penelitian Lo et al. (2018) dan Gouveia et al. (2016) melibatkan sampel kedua orang tua, berbeda dengan penelitian ini yang hanya melibatkan ibu saja. Hasil ini dapat dipahami dalam kaitannya dengan perbedaan karakteristik laki-laki dan perempuan. Dibandingkan laki-laki, perempuan memiliki karakteristik yang cenderung lebih empati, lebih sensitif dan secara normatif lebih diharapkan menjalankan peran-peran pengasuhan yang memungkinkan mereka secara naluriah lebih mampu menerapkan perilaku dan sikap hangat dan penuh kasih sayang terhadap anak (Gouveia et al., 2016) tanpa bergantung pada usia ataupun tingkat pendidikan. Temuan ini menunjukkan bahwa mindful parenting tidak dapat diprediksi dari variabel yang bersifat objektif. Dengan kata lain, variabel yang bersifat subjektif dan perseptual ditemukan lebih mampu memprediksi mindful parenting pada ibu di Indonesia. Hal ini diperkirakan karena faktor subjektif berbicara tentang penghayatan ibu tentang peran ataupun kompetensi pengasuhan yang mereka miliki sehingga cenderung lebih mampu membantu ibu untuk mindful dalam menjalankan peran pengasuhan.

\section{SIMPULAN DAN SARAN}

Mindful parenting pada ibu di Indonesia tidak dapat diprediksi dari faktor-faktor objektif seperti usia, latar belakang pendidikan dan pengetahuan tentang pengasuhan efektif, melainkan dapat diprediksi melalui faktor subjektif, yaitu kognisi pengasuhan baik positif maupun negatif. Kognisi pengasuhan positif yang diwakili oleh rasa kompeten pengasuhan diketahui dapat meningkatkan mindful parenting. Sebaliknya, kognisi pengasuhan yang negatif yang diwakili oleh atribusi berpusat pada orang tua diketahui dapat menurunkan mindful parenting. Orang tua yang merasa lebih kompeten dan memiliki atribusi yang rendah menjadi lebih mindful dalam menjalankan peran pengasuhan.

Penelitian ini memiliki keterbatasan, antara lain sampel yang diambil secara insidental menyebabkan sebaran yang tidak merata diperoleh dari berbagai pulau dan mewakili populasi di Indonesia. Selain itu, penelitian ini merupakan studi cross-sectional, maka hubungan sebab akibat tidak dapat diuji secara langsung seperti halnya penelitian longitudinal yang biasanya menggunakan pendekatan eksperimental, dengan metode intervensi mindfulness dan mindful parenting untuk keluarga, khususnya orang tua. Lebih lanjut, pengisian data penelitian menggunakan sistem daring juga menyebabkan sebaran data yang tidak merata karena tidak menyentuh ibu yang tidak menggunakan telepon genggam atau sarana daring lainnya, serta tidak terbiasa dengan pengisian sistem daring ini.

Berdasarkan hasil penelitian yang menemukan pengaruh tingginya rasa kompeten pengasuhan dan rendahnya atribusi berpusat pada orang tua terhadap mindful parenting, diharapkan dapat dimanfaatkan pihak terkait, seperti kader posyandu dan pengelola puskesmas untuk memberikan pelatihan mengembangan kognisi pengasuhan yang positif dan menurunkan kognisi pengasuhan yang negatif guna meningkatkan mindful parenting bagi para lbu. Selain itu, dapat pula digalakkan kampanye yang menumbuhkan rasa kompeten pada ibu bahwa mereka mampu melakukan pengasuhan yang baik. Lebih lanjut, perlu juga dilakukan kampanye terhadap orang-orang di sekeliling ibu untuk memberikan dukungan positif agar para ibu merasa kompeten dalam mengasuh anak dan tidak langsung menyalahkan ibu atas perilaku negatif yang dilakukan anak. Para ibu dapat memupuk rasa kompeten di dalam mengasuh dengan melakukan aktivitas yang dapat meningkatkan kompetensi, seperti membaca artikel terkait pengasuhan dan mengikuti pelatihan terkait pengasuhan.

\section{UCAPAN TERIMA KASIH}

Peneliti mengucapkan terima kasih sebesarbesarnya kepada Universitas YARSI yang telah memberikan dana hibah untuk mendanai penelitian ini secara penuh.

\section{DAFTAR PUSTAKA}

Aritonang, S. D., Hastuti, D., \& Puspitawati, H. (2020). Pengasuhan ibu, keterlibatan ayah dalam pengasuhan, dan perkembangan kognitif anak usia 2-3 tahun di wilayah prevalensi stunting. Jurnal Ilmu Keluarga \& Konsumen, 13(1), 38-48. doi:10.24156/jikk.2020.13.1.38.

Bandura, A. (2012). On the functional properties of perceived self-efficacy revisited. Journal of Management, 38(1), 9-44. doi:10.1177/0149206311410606.

Benedetto, L., \& Ingrassia, M. (2018). Parental self-efficacy in promoting children care and parenting quality. Parenting - Empirical Advances and Intervention Resources. doi:10.5772/intechopen.68933.

Berry, J. O., \& Jones, W. H. (1995). The parental stress scale: Initial psychometric 
evidence. Journal of Social and Personal Relationships, 12(3), 463-472. doi: 10.1177/0265407595123009.

Bluth, K., \& Wahler, R. G. (2011). Does effort matter in mindful parenting?. Mindfulness, 2(3), 175-178. doi:10.1007/ s12671-0110056-3.

Bögels, S. M., Hellemans, J., Deursen, S. V, Römer, M., \& Meulen, R. V. D (2014). Mindful parenting in mental health care: Effects on parental and child psychopathology, parental stress, parenting, coparenting, and marital functioning. Mindfulness, 5(5), 536-551. doi:10.1007/s12671-013-0209-7.

Bornstein, M. H., Putnick, D. L., \& Lansford, J. E. (2011). Parenting attributions and attitudes in cross-cultural perspective. Parenting, 11(2-3), 214-237. doi: 10.1080/15295192.2011.585568.

Bornstein, M. H., Putnick, D. L., \& Suwalsky, J. T. D. (2018). Parenting cognitions, parenting practices, child adjustment? The standard model. Development and Psychopathology, 30(2), 399-416. doi: 10.1017/S0954579417000931.

Bugental, D. B., New, M., Johnston, C., \& Silvester, J. (1998). Measuring parental attributions: Conceptual and methodological issues. Journal of Family Psychology, 12(4), 459-480. doi: 10.1037/0893-3200.12.4.459.

Chung, G., Lanier, P., \& Wong, P. Y. J. (2020). Mediating effects of parental stress on harsh parenting and parent-child relationship during coronavirus (COVID19) pandemic in Singapore. Journal of Family Violence. doi:10.1007/s10896-02000200-1.

Cluver, L., Meinck, F., Yakubovich, A., Doubt, J., Redfern, A., Ward, C., Salah, N., De Stone, S., Petersen, T., Mpimpilashe, P., Romero, R. H., Ncobo, L., Lachman, J., Tsoanyane, S., Shenderovich, Y., Loening, H., Byrne, J., Sherr, L., Kaplan, L., \& Gardner, F. (2016). Reducing child abuse amongst adolescents in low- and middleincome countries: A pre-post trial in South Africa. BMC Public Health, 16(1), 1-11. doi:10.1186/s12889-016-3262-z.

Dumka, L. E., Gonzales, N. A., Wheeler, L. A., \& Millsap, R. E. (2010). Parenting selfefficacy and parenting practices over time in Mexican American families. Journal of Family Psychology, 24(5), 522-531. doi:10.1037/a0020833.
Duncan, L. G., Coatsworth, J. D., \& Greenberg, M. T. (2009). A model of mindful parenting: Implications for parent-child relationships and prevention research. Clinical Child and Family Psychology Review, 12(3), 255270. doi:10.1007/s10567-009-0046-3.

Farb, N. A. S., Anderson, A. K., \& Segal, Z. V. (2012). The mindful brain and emotion regulation in mood disorders. Canadian Journal of Psychiatry, 57(2), 70-77. doi: $10.1177 / 070674371205700203$.

Gani, I. A. A., \& Kumalasari, D. (2019). Be mindful, less stress: Studi tentang mindful parenting dan stres pengasuhan pada lbu dari anak usia middle childhood di Jakarta. Jurnal Psikologi, 15(2), 98-107. doi:10.24014/ jp.v14i2.7744.

Gibaud-Wallston, J., \& Wandersman, L. P. (1978). Parenting sense of competence scale (PSOC). 5-6. Retrieved from http://psych.ubc.ca/persons/charlottejohnston/\%0Ahttps://psychology.ucalgary.c a/profiles/eric-mash.

Gouveia, M. J., Carona, C., Canavarro, M. C., \& Moreira, H. (2016). Self-compassion and dispositional mindfulness are associated with parenting styles and parenting stress: The mediating role of mindful parenting. Mindfulness, 7(3), 700-712. doi: 10.1007/s12671-016-0507-y.

Irzalinda, V., Puspitawati H., \& Muflikhati, I. (2014). Aktivitas bersama orang tua-anak dan perlindungan anak meningkatkan kesejahteraan subjektif anak. Jurnal IImu Keluarga dan Konsumen, 7(1), 40-47. doi:10.24156/jikk.2014.7.1.40.

Johnston, K. A., \& Taylor, M. (2018). The handbook of communication engagement (Eds.). New Jersey, NJ: John Wiley \& Sons.

[Kemen PPPA] Kementerian Pemberdayaan Perempuan dan Perlindungan Anak. (2020). Angka Kekerasan terhadap Anak Tinggi di Masa Pandemi, Kemen PPPA Sosialisasikan Protokol Perlindungan Anak. Jakarta, ID: Kemen PPPA.

[Kemen PPPA] Kemenetrian Pemberdayaan Perempuan dan Perlindungan Anak. (2020). Pengasuhan yang Baik, Tekan Potensi Kekerasan pada Anak. Jakarta, ID: Kemen PPPA.

Knerr, W., Gardner, F., \& Cluver, L. (2013). Improving positive parenting skills and reducing harsh and abusive parenting in low- and middle-income countries: A systematic review. Prevention Science, 
14(4), 352-363. doi:10.1007/s11121-0120314-1/.

Kumalasari, D., \& Fourianalistyawati, E. (2020). The role of mindful parenting to the parenting stress in mother with children at early age. Jurnal Psikologi, 19(2), 135142. doi:10.14710/jp.19.2.135-142.

Lestari, S. (2012). Psikologi keluarga: Penanaman nilai \& penanganan konflik dalam keluarga. Jakarta, ID: Kencana Prenamedia Group.

Lippold, M. A., Jensen, T. M., Duncan, L. G., Nix, R. L., Coatsworth, J. D., \& Greenberg, M. T. (2019). Mindful parenting, parenting cognitions, and parent-youth communication: Bidirectional linkages and mediational processes. Mindfulness. doi:10.1007/s12671-019-01119-5.

Lo, H. H. M., Yeung, J. W. K., Duncan, L. G., Ma, Y., Siu, A. F. Y., Chan, S. K. C., Choi, C. W., Szeto, M. P., Chow, K. K. W., \& Ng, S. M. (2018). Validating of the interpersonal mindfulness in parenting scale in Hong Kong-Chinese. Mindfulness, 9(5), 1390-1401. doi:10.1007/s12671-0170879-7.

Meunier, J. C., Roskam, I., \& Browne, D. T. (2011). Relations between parenting and child behavior: Exploring the child's personality and parental self-efficacy as third variables. International Journal of Behavioral Development, 35(3), 246-259. doi:10.1177/0165025410382950.

Neece, C. L. (2014). Mindfulness-based stress reduction for parents of young children with developmental delays: Implications for parental mental health and child behavior problems. Journal of Applied Research in Intellectual Disabilities, 27(2), 174-186. doi:10.1111/jar.12064.

Oates, J. (2010). Supporting parenting (Vol. 5). Milton Keynes, UK: The Open University.

Park, J. L., Johnston, C., Colalillo, S., \& Williamson, D. (2016). parents' attributions for negative and positive child behavior in relation to parenting and child problems. Journal of Clinical Child \& Adolescent Psychology, 47(Sup1), 1-13. doi:10.1080/15374416.2016.1144191.

Pranawati, R., Naswardi, \& Zulkarnaen, S. D. (2015). Kualitas pengasuhan anak Indonesia: Survei nasional dan telaah kebijakan pemenuhan hak pengasuhan anak di Indonesia. Jakarta, ID: Komisi Perlindungan Anak Indonesia.
Rachmawati, A. N., \& Hastuti, D. (2017). Parental self-efficacy dan praktik pengasuhan menentukan perilaku agresif anak usia pra sekolah. Jurnal IImu Keluarga dan Konsumen, 10(3), 227-237. doi:10.24156/jikk.2017.10.3.227.

Sanders, M. R., \& Morawska, A. (2018). Handbook of parenting and child development across the lifespan. Handbook of Parenting and Child Development Across the Lifespan, 1-853. doi:10.1007/978-3-319-94598-9.

Shumow, L., \& Lomax, R. (2002). Parental efficacy: Predictor of parenting behavior and adolescent outcomes. Parenting, Science and Practice, 2(2), 127-150. doi: 10.1207/S15327922PAR0202_03.

Slagt, M., Deković, M., de Haan, A. D., van den Akker, A. L., \& Prinzie, P. (2012). Longitudinal associations between mothers' and fathers' sense of competence and children's externalizing problems: The mediating role of parenting. Developmental Psychology, 48(6), 15541561. doi:10.1037/ a0027719.

Steinberg, L. (2004). The 10 basic principles of good parenting. New York, US: Simon \& Schuster.

Oord, S. V. D, Bögels, S. M., \& Peijnenburg, D. (2012). The Effectiveness of mindfulness training for children with ADHD and mindful parenting for their parents. Journal of Child and Family Studies, 21(1), 139-147. doi:10.1007/s10826-011-9457-0.

Wang, M., \& Wang, J. (2018). Negative parental attribution and emotional dysregulation in Chinese early adolescents: Harsh fathering and harsh mothering as potential mediators. Child Abuse and Neglect, 81(October 2017), 12 20. doi:10.1016/ j.chiabu.2018.04.008.

Widarsson, M., Engström, G., Rosenblad, A., Kerstis, B., Edlund, B., \& Lundberg, P. (2013). Parental stress in early parenthood among mothers and fathers in Sweden. Scandinavian Journal of Caring Sciences, 27(4), 839-847. doi:10.1111/j.14716712.2012.01088.x.

Winter, L., Morawska, A., \& Sanders, M. (2012). The knowledge of effective parenting scale (KEPS): A tool for public health approaches to universal parenting programs. Journal of Primary Prevention, 33(2-3), 85-97. doi:10.1007/s10935-0120268-x. 